\title{
Spectrophotometric Determination of Tiopronin Using Its Catalytic Reaction between Sodium 1,2-Naphthoquinone-4-sulfonate and Hydroxyl Ion
}

\author{
Quanmin $\mathrm{Li}^{\dagger}$ and Linxiao GAO \\ College of Chemistry and Environmental Science, Henan Normal University, The Key Laboratory of \\ Environmental Pollution Control Technology of Henan Province, Xinxiang, Henan 453007, P. R. China
}

\begin{abstract}
A novel and simple spectrophotometric method for the determination of tiopronin with sodium 1,2-naphthoquinone-4sulfonate (NQS) is established in this paper. The detailed mechanism is proposed and discussed. It is based on the fact that tiopronin can catalyze the reaction between sodium 1,2-naphthoquinone-4-sulfonate and hydroxyl ion to form 2-hydroxy-1,4-naphthoquinone in a buffer solution of $\mathrm{pH} 13.00$ at the maximal absorption wavelength of $445 \mathrm{~nm}$. When tetradecyl benzyl dimethyl ammonium chloride (Zeph) is added to the solution, the sensitivity of the reaction is improved. Beer's law is obeyed in a range of $0.39-15.67 \mu \mathrm{g} \mathrm{mL}^{-1}$. The equation of linear regression is $A=0.11749+0.05914 C$ $\left(\mu \mathrm{g} \mathrm{mL} \mathrm{m}^{-1}\right)$, with a linear correlation coefficient of 0.9973 . The detection limit is $0.2 \mu \mathrm{g} \mathrm{mL}^{-1}$, RSD is $0.88 \%$ and the recovery rate is in the range of $96.6-103.9 \%$. Furthermore, the method has been validated and successfully applied to the determination of tiopronin in pharmaceutical samples.
\end{abstract}

(Received January 28, 2008; Accepted May 14, 2008; Published January 10, 2009)

\section{Introduction}

Tiopronin ( $N$-(2-mercaptopropionyl)glycine, TP) is a synthetic thiol compound that has been used as an antidote to heavy metal poisoning and a radioprotective agent. It has also been successfully applied to prevent kidney stones, and to treat cystinuria, rheumatoid arthritis, hepatic disorders. ${ }^{1-4}$ Additionally, tiopronin has a relatively high frequency of side effects, such as the loss of taste or upset stomach, muscle pain, sore throat and fever.

Many different methods have been widely reported for the determination of tiopronin, such as flow-injection analysis, ${ }^{1}$ reverse-phase high-performance liquid chromatography, ${ }^{2}$ electron spray ionization mass spectrometry, ${ }^{3}$ chemiluminescent, ${ }^{4,5}$ fluorometric method, ${ }^{6}$ LC-ESI-MS, LC-ESI-MS-MS, ${ }^{8}$ etc. However, in almost all of the methods mentioned above, some laborious sample treatment, expensive apparatus, and complex derivation steps are needed. Obviously, it is very significant to find a sensitive, accurate and simple method to determine TP in research involving clinical medicine.

It was reported in 1894 that sodium1,2-naphthoquinone-4sulfonate (NQS) could react with the amino group of the primary amine derivative. ${ }^{9}$ In this paper, a spectrophotometric method for the determination of TP in pharmaceutical samples is presented. When Zeph is added to the system, the absorbance increases distinctly. In contrast with the methods mentioned above, ${ }^{1-8}$ the proposed method is simple and fast with a high sensitivity. Analytical results obtained by this new method were very gratifying.

† To whom correspondence should be addressed. E-mail: mercury6068@hotmail.com

\section{Experimental}

Apparatus

A Model T6 spectrophotometer (Pgeneral Instrument Plant, Beijing, China) was used for photometric measurements and recording the absorption spectrum. A Model CS-501 super constant temperature instrument (Chongqing Experiment Equipment Plant, Chongqing, China) was employed for temperature measurements and controlling. All $\mathrm{pH}$ measurements were made with a $\mathrm{pH}-3 \mathrm{C}$ digital $\mathrm{pH}$ meter (Shanghai Lei Ci Device Works, Shanghai, China); IR spectra were taken by the $\mathrm{KBr}$ pelletization method using FTS-40 Fourier-transform infrared spectrometric (American BIO-RAO Company, USA). The ${ }^{1} \mathrm{H}-\mathrm{NMR}$ spectra were recorded with Bruker $400 \mathrm{MHz}$ ultra shield ${ }^{\mathrm{TM}}$ NMR spectrometer (The Bruker Companies, Germany) using $\mathrm{CD}_{3} \mathrm{OD}$ as a solvent; 6890GC5973N GC-MS (Agilent Technologies Company, California, USA) was used to carry out on MS spectrum analysis.

\section{Reagents}

A solution of $5.0 \times 10^{-3} \mathrm{M}$ NQS was prepared by dissolving $0.3252 \mathrm{~g} \mathrm{NQS}$ (from ACROSORGANICS) in distilled water, transferring it into a $250-\mathrm{mL}$ volumetric flask, diluting to the mark, mixing well and preserving at $4^{\circ} \mathrm{C}$ without light. A standard solution of $1.5 \times 10^{-3} \mathrm{M}$ tiopronin (Xinyi Medicine Plant, Xinxiang China) was prepared and preserved at $4^{\circ} \mathrm{C}$ without light. A buffer solution of $\mathrm{pH} 13.00$ was prepared by mixing a $125-\mathrm{mL}$ solution of $\mathrm{KCl}(0.20 \mathrm{M})$ and a $330-\mathrm{mL}$ solution of $\mathrm{NaOH}(0.20 \mathrm{M})$ in a $500-\mathrm{mL}$ standard flask. Unless otherwise stated, analytical reagent-grade chemicals and distilled water were used throughout. 


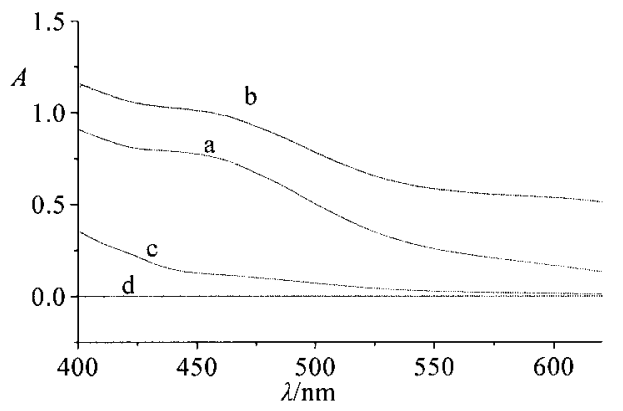

Fig. 1 Absorption spectrum. a, Product I against a reagent blank; b, product II against a reagent blank; c, NQS at pH 13.00 against water; $\mathrm{d}, \mathrm{TP}$ at $\mathrm{pH} 13.00$ against water.

\section{General procedures}

About $1.00 \mathrm{~mL}$ of $1.5 \times 10^{-3} \mathrm{M}$ TP, a $3.50-\mathrm{mL}$ buffer solution of $\mathrm{NaOH}-\mathrm{KCl}(\mathrm{pH} 13.00)$ and a $2.50-\mathrm{mL}$ solution of $\mathrm{NQS}$, and subsequently, $1.00 \mathrm{~mL}$ of a $0.1 \%$ solution of Zeph were transferred into a $12.5-\mathrm{mL}$ color comparison tube, and diluted to the mark with distilled water and mixed well. This solution was left standing for $30 \mathrm{~min}$ at room temperature, and the absorbance of the solution was measured at $445 \mathrm{~nm}$ against a reagent blank prepared with the same reagent concentration, but no TP.

\section{Preparation of the reaction product}

About $0.0112 \mathrm{~g}$ of TP was transferred into a $50-\mathrm{mL}$ beaker. Subsequently, $8.00 \mathrm{~mL}$ of a buffer solution of $\mathrm{NaOH}-\mathrm{KCl}(\mathrm{pH}$ 13.00) and $25.00 \mathrm{~mL}$ of a solution of NQS were added to it and mixed well. After left standing for $30 \mathrm{~min}$ at room temperature, the solution was adjusted to acidity by using $5.00 \mathrm{~mL}$ of a solution of hydrochloric acid $(0.20 \mathrm{M})$. Under a constant temperature of $40^{\circ} \mathrm{C}$, the solution was heated until almost dryness, and the reaction product was obtained. Then, after being washed with distilled water to neutrality, the reaction product was dried for $1 \mathrm{~h}$ at a constant temperature of $40^{\circ} \mathrm{C}$. The product was used for IR, MS, ${ }^{1} \mathrm{H}-\mathrm{NMR}$ analysis.

\section{Results and Discussion}

\section{Absorption spectrum}

As shown in Fig. 1, the disparity of absorbency between product I and NQS is larger and the absorption peak of product I; product II is comparatively smoothness. Moreover, the addition of Zeph improved the sensitivity of the TP-NQS-buffer solution system to a much higher level. In order to obtain higher sensitivity and to eliminate reagent interference, all measurements were carried out at $445 \mathrm{~nm}$ against a reagent blank in the latter experiment.

\section{Discussion of the reaction mechanism}

Detection of sulfurous ion $\left(\mathrm{SO}_{3}{ }^{2-}\right)$ in a sample solution. According to the procedure, a sample solution (solution I) and a reagent blank solution (solution II) were prepared, respectively. These solutions were left standing for $30 \mathrm{~min}$ at room temperature. Then, $5.00 \mathrm{~mL} 10 \% \mathrm{BaCl}_{2}$ was added into solution I and solution II, respectively, while shaking these solutions. It was found that white precipitation appeared in solution I, but a similar phenomenon did not occur in solution II. After centrifugal separation, a solution of $0.20 \mathrm{M} \mathrm{HCl}$ was added to the white precipitation obtained from solution I. It was found that a gas with a pungent smell was given off from the solution,

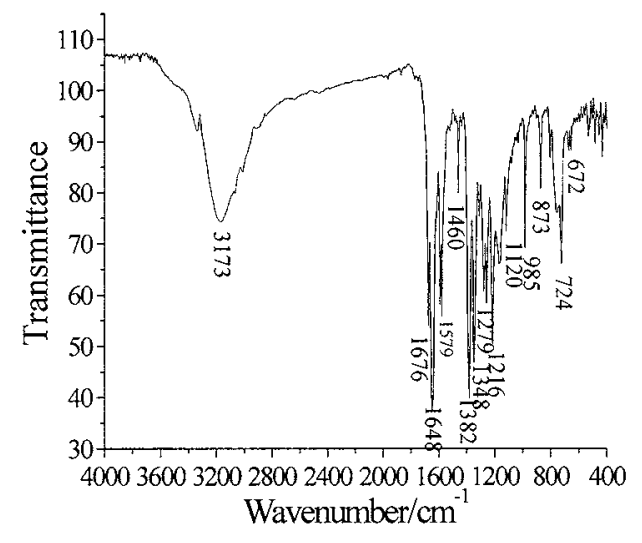

Fig. 2 IR spectrum.

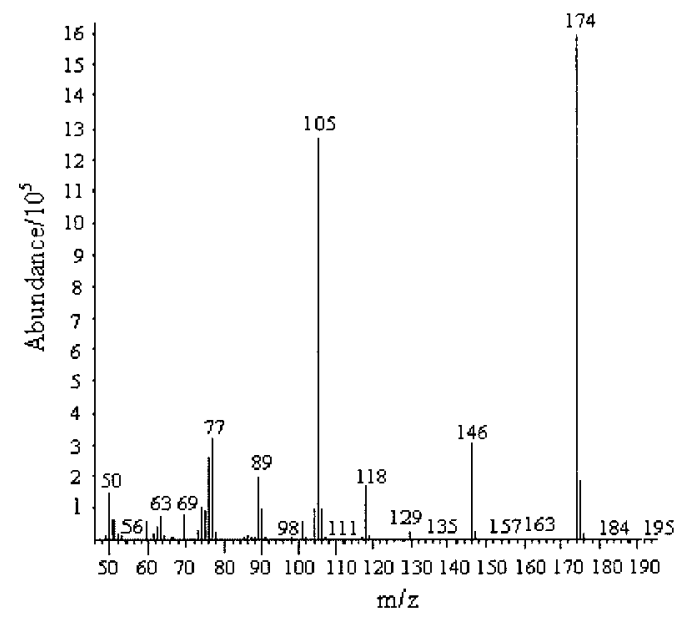

Fig. 3 MS spectrum.

the white precipitation was dissolved, and the gas could make basic fuchsin discolor, indicating that the gas was $\mathrm{SO}_{2}$. Therefore, it was presumed that there was $\mathrm{SO}_{3}{ }^{2-}$ in solution I containing TP; in other words, in the $\mathrm{NaOH}-\mathrm{KCl}$ buffer solution of $\mathrm{pH} 13.00$, 4-sodium sulfonate of NQS was substituted by hydroxyl ion in the form of $\mathrm{SO}_{3}{ }^{2-}$ in the presence of TP.

$I R, M S, I H-N M R$ spectrum analysis. The reaction product obtained from the method mentioned above was carried out in IR, MS and ${ }^{1} \mathrm{H}-\mathrm{NMR}$ analysis, respectively. It can be seen that the IR (Fig. 2), MS (Fig. 3), and ${ }^{1} \mathrm{H}-\mathrm{NMR}$ (Fig. 4) spectra are almost the same as the standard spectrum of 2-hydroxy-1,4naphthoquinone, indicating that the reaction between NQS and hydroxyl ion can take place in the presence of TP.

Keeping all other conditions unchanged, the residue was obtained according to the experimental method mentioned above in the absence of TP. It was found that MS spectrum of the residue was the same as that of NQS. This indicates that the reaction between NQS and the hydroxyl ion can not take place in the absence of TP.

Composition ratio and reaction mechanism of TP and NQS. Based on the continuous variation method of equivalent mole (Fig. 5) and the slope ratio method (Fig. 6), we found that the stoichiometric ratio of the reaction between TP and NQS is 1:2, and the molecular structure of product I (2-hydroxy-1,4naphthoquinone, i.e. lawsone) does not contain groups of TP, which indicates that TP plays the role of a catalyst. It has also been reported that NQS could react with amine reagents and 


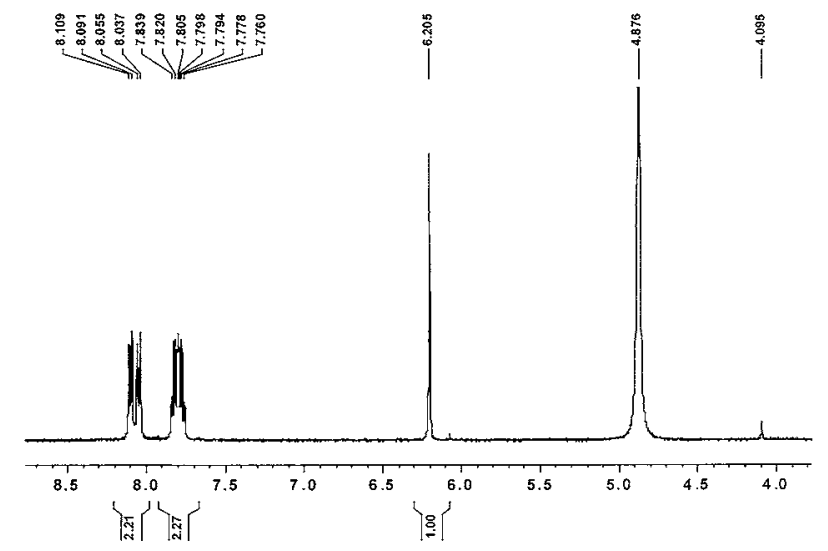

Fig. $4 \quad{ }^{1} \mathrm{H}-\mathrm{NMR}$ spectrum.

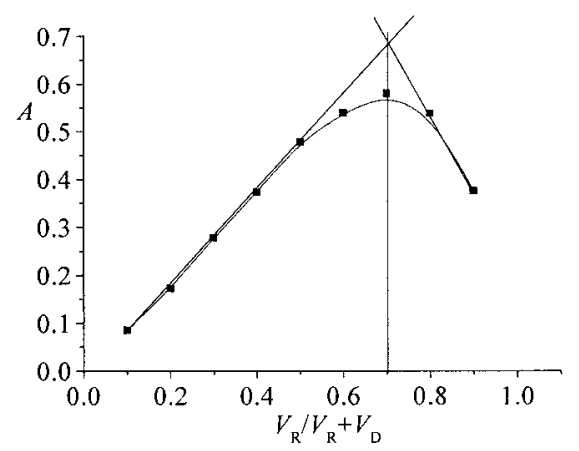

Fig. 5 Determination of product $I$ formation by the continuous variation method of equivalent mole. $V_{\mathrm{D}}, \mathrm{TP}\left(1.5 \times 10^{-3} \mathrm{M}\right) ; V_{\mathrm{R}}$, NQS $\left(1.5 \times 10^{-3} \mathrm{M}\right) ; V_{\mathrm{D}}+V_{\mathrm{R}}=5.00 \mathrm{~mL}$; reaction time, $30 \mathrm{~min}$; total volume, $12.5 \mathrm{~mL}$.

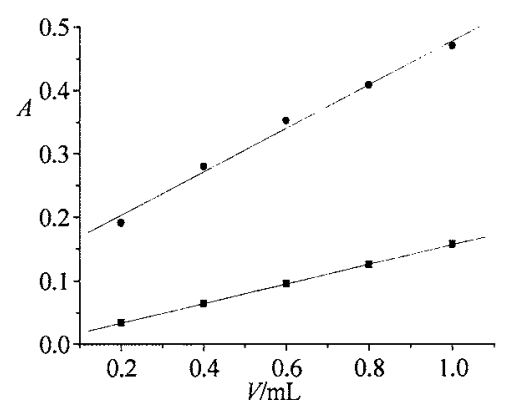

Fig. 6 Determination of product $I$ formation by the slope ratio method. $V_{\mathrm{D}}$, TP $\left(1.5 \times 10^{-3} \mathrm{M}\right) ; V_{\mathrm{R}}$, NQS $\left(1.5 \times 10^{-3} \mathrm{M}\right)$; reaction time, $30 \mathrm{~min}$; total volume, $12.5 \mathrm{~mL}$.

their ramifications due to the fact that its lone pairs of electron on nitrogen can attack the electron deficiency center in NQS, ${ }^{9}$ namely the No. 4 carbon atom. In pH 13.00, TP exists in the form of the corresponding anion of dipolar ion, and the hydrogen atom of hydrosulfonyl is also dissociated, which makes sulfur have nucleophilicity. It is thus concluded that the anion formed by ionization of TP reacts with NQS to form an unstable intermediate, which is then replaced by $\mathrm{OH}^{-}$to form unsymmetrical 4-hydroxy-1,2-naphthoquinone, having a structure of the enol form, and is furthermore converted into comparatively steady 2-hydroxy-1,4-naphthoquinone.

After Zeph is added to the solution, systematic absorbency obviously augments. It is presumable that Zeph is a quaternary ammonium salt, whose nitrogen atom with positive charge can make an ion-association compound with the anion of 2-hydroxy1,4-naphthoquinone. Then, a bigger conjugated system was formed, which led to an increase of the area of absorption. Thus, sensitization for the reaction of TP-NQS was distinctly improved. It seems reasonable that the reaction equation is as follows.

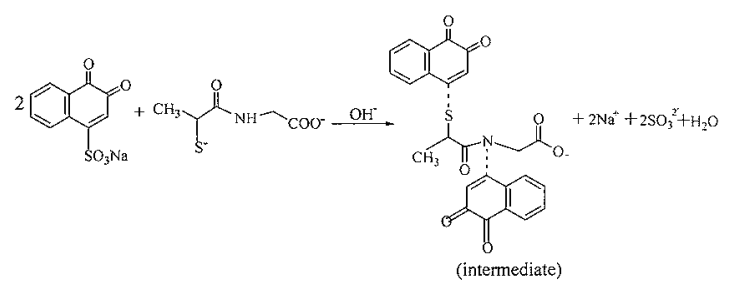

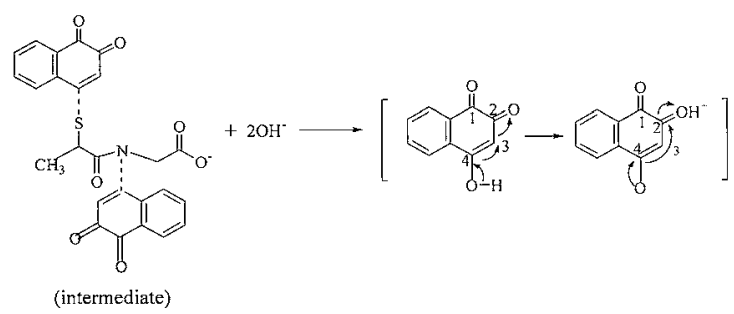<smiles>Cc1ccc2c(c1)C(=O)C(O)=CC2=O</smiles>

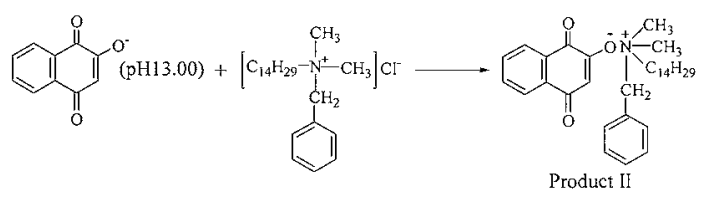

Effect of the $\mathrm{pH}$

The effect of the $\mathrm{pH}$ on the determination of TP with NQS was examined by varying it from 1.00 to 14.00 . The absorbance of the reaction was close to 0 in the range of $\mathrm{pH} 1.00-12.00$, which indicates that it is difficult for the catalytic reaction to take place. A possible reason is that the concentration of the anion ionized by the dipolar ion of TP is lower when the $\mathrm{pH}$ is less than 12.00. Thus, the nucleophilic capacity on 4-sodium sulfonate of NQS depressed, and the nucleophilic substitution reaction does not take place easily. When the $\mathrm{pH}$ is more than 12.00 , the absorbance begins to increase, and reaches the maximum value at $\mathrm{pH}$ 13.00. Presumably, the amount of the anion ionized by dipolar ion of TP increases with an increase of the $\mathrm{pH}$. Thus, the nucleophilic substitution reaction occurs more easily between the anion ionized by TP and NQS. In order to keep the high sensibility for the determination of TP, $\mathrm{pH} 13.00$ was chosen for subsequent experiments.

\section{Effect of NQS}

Keeping amount of TP and the buffer solution constant, the amount of NQS, ranging from 0.50 to $3.50 \mathrm{~mL}$, was submitted to the proposed procedure. It was found that the absorbance increased rapidly with an increase in the amount of NQS, and became maximal and constant when the amount of NQS was $2.50 \mathrm{~mL}$ or greater. Thus, $2.50 \mathrm{~mL}$ of NQS solution was chosen.

Effect of the temperature and buffer solution

The absorbance of the reaction was determined at different 


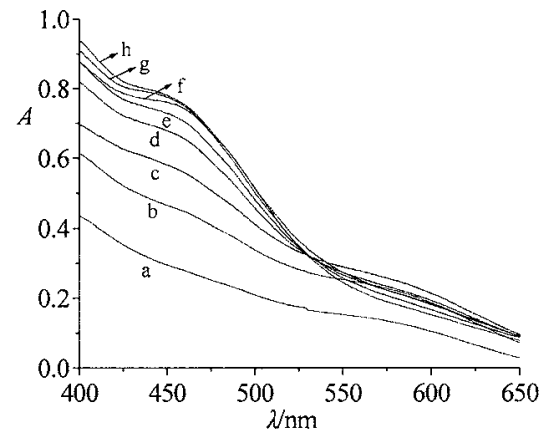

Fig. 7 Scan absorption spectrum for different reaction time. $\mathrm{a}-\mathrm{h}$ represents the scan absorption spectrum for $1,2,3,5,10,20,30,35$ min, respectively.

temperatures with a 5-min reaction time. With the temperature increasing, the absorbance gradually decreased. In order to make the determination simpler, the room temperature was chosen as the optimum. In addition, keeping the $\mathrm{pH}$ at 13.00, the effect of the amount of buffer solution on the absorbance was researched. The absorbance was enhanced remarkably with an increase in the amount of buffer solution, and reached the maximum when $3.50 \mathrm{~mL}$ of a $\mathrm{NaOH}-\mathrm{KCl}$ buffer solution ( $\mathrm{pH} 13.00)$ was added. Therefore, $3.50 \mathrm{~mL}$ of a buffer solution was chosen.

\section{Scan absorption spectrum of different reaction time}

The scan absorption spectrum of different reaction time is drawn in Fig. 7 at room temperature. The shapes of the scan absorption spectrum $3 \mathrm{~min}$ before and $5 \mathrm{~min}$ later have distinct differences. It is probable that the product is mainly in the form of an intermediate from 1 to $3 \mathrm{~min}$, and that the shapes of the scan absorption spectrum are similar to each other after $5 \mathrm{~min}$; the intermediate probably transformed into product I. It can be found that the TP reacts immediately with NQS, the absorbance reaches the maximum value at $30 \mathrm{~min}$, and remains constant for at least $40 \mathrm{~min}$, and so a reaction time of $30 \mathrm{~min}$ was chosen.

\section{Effect of surfactants}

While keeping all other experiment conditions constant, the effects of surfactants on the determination of TP are shown in Fig. 8. OP-10 $(0.1 \%)$ of a nonionic surfactant, CTMAB $(0.1 \%)$ of a cationic surfactant and SLS $(0.1 \%)$ of an anion surfactant can hardly affect the results when they are added in the range of $0.20-2.00 \mathrm{~mL}$, respectively. However, when Zeph $(0.1 \%)$ of a cationic surfactant is added to the solution, the absorbance distinctly increases. It is presumable that Zeph is a quaternary ammonium salt, whose nitrogen atom with positive charge can make an ion-association compound with product I.

\section{Potential interference}

A systematic study of the influence of common ions was carried out in the determination of TP. The tolerance levels were defined with an error of less than $\pm 5 \%$ in the analysis. The following conclusion is drawn: concentrations of $3392 \mathrm{mg} \mathrm{L}^{-1}$ $\left(\mathrm{CO}_{3}{ }^{2-}\right), 2384 \mathrm{mg} \mathrm{L}^{-1}\left(\mathrm{~K}^{+}, \mathrm{Na}^{+}, \mathrm{Cl}^{-}, \mathrm{SO}_{4}{ }^{2-}\right), 1428 \mathrm{mg} \mathrm{L}^{-1}\left(\mathrm{Br}^{-}\right)$, $86 \mathrm{mg} \mathrm{L}^{-1}\left(\mathrm{NO}_{3}^{-}\right), 48 \mathrm{mg} \mathrm{L}^{-1}\left(\mathrm{Mg}^{2+}\right), 6 \mathrm{mg} \mathrm{L}^{-1}\left(\mathrm{Ni}^{2+}\right), 1.6 \mathrm{mg} \mathrm{L}^{-1}$ $\left(\mathrm{Cu}^{2+}\right), 1.2 \mathrm{mg} \mathrm{L}^{-1}\left(\mathrm{Zn}^{2+}\right), 0.8 \mathrm{mg} \mathrm{L}^{-1}\left(\mathrm{Co}^{2+}\right)$ or less did not affect the determination of TP. As can be seen above, the tolerant concentrations of $\mathrm{Co}^{2+}, \mathrm{Ni}^{2+}, \mathrm{Cu}^{2+}, \mathrm{Zn}^{2+}$ and $\mathrm{Mg}^{2+}$ are relatively low, probably because these metal ions can react with the thiol group of TP, which results in a decrease in the effective concentration of TP that can react with NQS. It holds back the nucleophilic substitution reaction between TP and NQS.

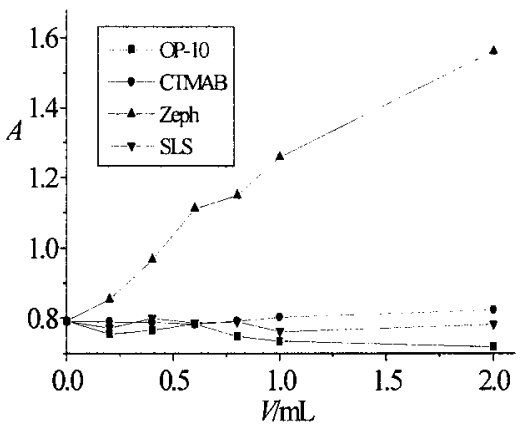

Fig. 8 Effect of the surfactant. TP $\left(1.5 \times 10^{-3} \mathrm{M}\right), 1.00 \mathrm{~mL}$; NQS $\left(5.00 \times 10^{-3} \mathrm{M}\right), 2.50 \mathrm{~mL}$; NaOH-KCL buffer solution $(\mathrm{pH} 13.00)$, $3.50 \mathrm{~mL}$; reaction time, $30 \mathrm{~min}$; total volume, $12.5 \mathrm{~mL}$.

Table 1 Apparent rate constant and activation energy

\begin{tabular}{cccc}
\hline \multirow{2}{*}{ Sample } & \multicolumn{2}{c}{$k / \mathrm{s}^{-1}$} & \multirow{2}{c}{$E_{\mathrm{a}} / \mathrm{kJ} \mathrm{mol}^{-1}$} \\
\cline { 2 - 3 } & $40^{\circ} \mathrm{C}$ & $50^{\circ} \mathrm{C}$ & \\
\hline Tiopronin & $1.13 \times 10^{-3}$ & $1.42 \times 10^{-3}$ & 19.20 \\
\hline
\end{tabular}

\section{Equation of the calibration curve}

Figure 8 has shown that the system TP-NQS can be improved by Zeph to a much higher level; in other words, Zeph can enhance the sensitivity of the proposed reaction. Then, the absorbance of the system TP-NQS-Zeph was determined under the optimum conditions. A linear-regression equation was attained as $A=0.11749+0.05914 C\left(\mu \mathrm{g} \mathrm{mL}^{-1}\right)$ with a linearly dependent coefficient of 0.9973 , and $\varepsilon_{445}$ is $9.7 \times 10^{3} \mathrm{~L} \mathrm{~mol}^{-1}$ $\mathrm{cm}^{-1}$. The liner range of TP is $0.39-15.67 \mu \mathrm{g} \mathrm{mL}^{-1}$.

According to the procedure, the solution of TP was determined 11 times $(n=11)$ with an RSD of $0.88 \%$. Then, a reagent blank solution was measured 11 times $(n=11)$, and the standard deviation of the reagent blank $(\sigma)$ was 0.003023 . Therefore, the detection limit $(3 \sigma)$ of this proposed method, evaluated from the calibration curve, is $0.2 \mu \mathrm{g} \mathrm{mL} \mathrm{m}^{-1}$.

\section{Apparent rate constant and activation energy}

By dealing with the obtained $A-T$ data, the apparent rate constants at 40 and $50^{\circ} \mathrm{C}$ can be obtained, respectively. Then, in light of the Arrhenius formula, $E_{\mathrm{a}}=R T_{2} T_{1} /\left(T_{2}-T_{1}\right) \cdot \ln k_{2} / k_{1}$, and different pairs of $K-T$ data, the activation energy of the nucleophilic substituent reaction between TP and NQS was calculated (Table 1). Because activation energy of the reaction is less than $40 \mathrm{~kJ} \mathrm{~mol}^{-1}$, the nucleophilic substituent reaction can probably take place easily.

\section{Sample Analysis}

In order to evaluate the validity of the proposed method for the determination of TP in pharmaceuticals, in accordance with the procedure, different concentrations of sample solutions were measured, so that their concentrations were in the linear range of TP given in the Table 2. The results agreed well with those obtained by the high-performance liquid chromatography method (HPLC). Since the sample used in the experiment was the compound prescripition, recovery tests of standard addition were also carried out. Table 2 indicates that other components (starch, dextrin and calcium stearate) in the pharmaceutical 
Table 2 Recovery of tiopronin in tablets

\begin{tabular}{cccccccc}
\hline Sample & $\begin{array}{c}\text { Sample content/ } \\
\mu \mathrm{g} \mathrm{mL}^{-1}\end{array}$ & $\begin{array}{c}\text { Proposed method/ } \\
\mu \mathrm{g} \mathrm{mL}^{-1}\end{array}$ & $\begin{array}{c}\text { HPLC method/ } \\
\mu \mathrm{g} \mathrm{mL}^{-1}\end{array}$ & $\begin{array}{c}\text { The added/ } \\
\mu \mathrm{g} \mathrm{mL}^{-1}\end{array}$ & $\begin{array}{c}\text { Found/ } \\
\mu \mathrm{g} \mathrm{mL} \mathrm{mL}^{-1}\end{array}$ & $\begin{array}{c}\text { Recovery, } \\
\%\end{array}$ & $\begin{array}{c}\text { RSD, \% } \\
n=5\end{array}$ \\
\hline 1 & 1.00 & 0.99 & 1.01 & 3.92 & 3.90 & 96.6 & 2.2 \\
2 & 2.00 & 2.02 & 2.01 & 5.88 & 5.98 & 101.8 & 1.9 \\
3 & 3.00 & 3.11 & 2.99 & 7.83 & 8.14 & 103.9 & 1.0 \\
4 & 5.00 & 4.95 & 5.01 & 7.83 & 7.76 & 99.0 & 0.8 \\
5 & 5.00 & 4.92 & 4.99 & 5.87 & 5.77 & 98.2 & 1.0 \\
\hline
\end{tabular}

sample did not affect the determination of the TP, and satisfactory recovery results were achieved for TP.

\section{Conclusion}

It is reported for the first time that TP can catalyze a reaction between NQS and hydroxyl ion to form lawsone. In a comparison with other methods mentioned in this paper, the presented procedure does not require any sophisticated instruments, and is simple, sensitive and rapid to be carried out. These merits make it applicable for common laboratories. Therefore, the present work is superior to the existing approaches for the determination of $\mathrm{TP}$ in pharmaceutical preparations with satisfactory results.

\section{References}

1. T. Pérez-Ruiz, C. Mnez-Lozano, W. R. G. Baeyens, A.
Sanz, and M. T. San-Miguel, J. Pharm. Biomed. Anal., 1998, 17, 823 .

2. T. M. Huang, B. Yang, Y. J. Yu, X. W. Zheng, and G. L. Duan, Anal. Chim. Acta, 2006, 565, 178.

3. A. P. Gies, D. M. Hercules, A. E. Gerdon, and D. E. Cliffel, J. Am. Chem. Soc., 2007, 129, 1095.

4. J. Z. Lu, C. Lau, S. Yagisawa, K. Ohta, and M. Kai, J. Pharm. Biomed. Anal., 2003, 33, 1033.

5. J. Ouyang, W. R. G. Baeyens, J. Delanghe, G. Van Der Weken, W. Van Daele, D. De Keukeleire, and A. M. G. Campanä, Anal. Chim. Acta, 1999, 386, 257.

6. J. Xu, R. X. Cai, J. Wang, Z. H. Liu, and X. G. Wu, J. Pharm. Biomed. Anal., 2005, 39, 334.

7. J. F. Liu, H. H. Wu, and Y. N. Hou, J. Chromatogr., B, 2006, 844,153

8. K. Matsuura, K. Murai, Y. Fukano, and H. Takashina, $J$. Pharm. Biomed. Anal., 2000, 22, 101.

9. M. Böniger, Ber., 1894, 27, 23. 